\title{
Suicide after traumatic brain injury: a population study
}

\author{
T W Teasdale, A W Engberg
}

\begin{abstract}
Objectives-To determine the rates of suicide among patients who have had a traumatic brain injury.
\end{abstract}

Methods-From a Danish population register of admissions to hospital covering the years 1979-93 patients were selected who had had either a concussion $(n=126114)$, a cranial fracture $(n=7560)$, or a cerebral contusion or traumatic intracranial haemorrhage $(n=11766)$. All cases of deaths by the end of the study period were identified.

Results-In the three diagnostic groups there had been $750(0.59 \%), 46(0.61 \%)$, and $99(0.84 \%)$ cases of suicide respectively. Standardised mortality ratios, stratified by sex and age, showed that the incidence of suicide among the three diagnostic groups was increased relative to the general population $(3.0,2.7$, and 4.1 respectively). In all diagnosis groups the ratios were higher for females than for males, and lower for patients injured before the age of 21 or after the age of 60 . The presence of a codiagnosis relating to substance misuse was associated with increased suicide rates in all diagnosis groups. There was a tendency, among patients with cerebral contusions or traumatic intracranial haemorrhages, for suicide risk to increase with duration of stay in hospital. Cox regression analyses for proportional hazards confirmed that there was a significantly greater risk of suicide among patients with cerebral contusions or traumatic intracranial haemorrhages than among patients with concussion or cranial fractures (hazard ratios $=1.42$ and 1.50 respectively). There was, however, no evidence of a specific risk period for suicide after injury.

Conclusion-The increased risk of suicide among patients who had a mild traumatic brain injury may result from concomitant risk factors such as psychiatric conditions and psychosocial disadvantage. The greater risk among the more serious cases implicates additionally the physical, psychological, and social consequences of the injuries as directly contributing to the suicides.

(F Neurol Neurosurg Psychiatry 2001;71:436-440)

Keywords: traumatic brain injury; concussion; suicide Dr T W Teasdale

teasdale@psy.ku.dk

Received 19 October 2000 and in revised form

12 February 2001

Accepted 12 March 2001 changes in all aspects of life, including employment, and family and social relationships. Profound emotional responses of anxiety and in particular major depression are not uncommon ${ }^{1-3}$ and suicidal ideation and suicide attempts after traumatic brain injury have also been reported. ${ }^{4-6}$

Owing to its comparative rarity, however, there have been only few studies which have examined the occurrence of completed suicide after traumatic brain injury. In a recent review, Harris and Barraclough ${ }^{7}$ listed six studies, all pre-1980, which together suggested increased rates of suicides among populations with brain injury. In by far the largest of these studies, Achté et $a l^{8}$ found 85 suicide cases among 6498 war veterans with brain injury. In another early study, Roberts ${ }^{9}$ found three cases of suicide in an up to 25 year follow up of 479 patients with traumatic brain injury. In more recent long term follow up studies, Wilson ${ }^{10}$ reported three suicides among 55 patients with traumatic brain injury, Klonoff and Lage ${ }^{11}$ found two suicides among a group of 111 patients from a rehabilitation programme and Tate et $a l^{12}$ reported eight suicides from among 896 patients.

Excepting that of Achté et al, the above studies comprise only 24 cases of suicide after traumatic brain injury. These small numbers make it difficult to assess the extent to which the rate of suicide after traumatic brain injury may be increased above the rate of the general population. The situation is further complicated by the fact that some risk factors for suicide in the general population are also risk factors for traumatic brain injury-for example, young adults, males, involvement of substance misuse, especially alcohol, ${ }^{13-15}$ and a range of other factors relating to psychosocial disadvantage. This means that any statistical association between traumatic brain injury and subsequent suicide could arise simply because of the association of both with such risk factors.

In the present study we have examined suicide rates among a large population derived sample of patients who had survived a traumatic cerebral lesion and who were followed up for a period of up to 15 years. To control for possible risk factors among these patients we have compared them with samples of patients, derived from the same population, who had either a concussion or a cranial fracture. These groups typically have fewer and much less severe sequella to their injuries but are generally similar in demographic and psychological characteristics. ${ }^{16}{ }^{17}$ Therefore, the extent to which suicide is found to be more 
common among survivors of cerebral contusions or traumatic intracranial haemorrhage than among the groups who had either a concussion or a cranial fracture would be suggestive of a direct associative link between that injury and the subsequent suicide.

\section{Methods}

DATA SOURCES

Subjects in the present study were identified in a computerised National Bureau of Health register of hospitalisations which documents all admissions to hospital in Denmark since 1979, including admission and discharge dates and discharge diagnoses. As part of a larger study the register was searched for all cases with a discharge, between the years 1979 and 1993 inclusive, with a main or secondary diagnosis of traumatic brain injury. During this period the International Classification of Diseases (ICD) 8 th edition codes were used in the register. On this basis we have therefore defined three groups.

(1) Concussion ICD 850

(2) Cranial fracture ICD 800, 801, 803

(3) Cerebral contusion/traumatic intracranial haemorrhage ICD 851-854

These groups are here termed "concussion", "fracture", and "lesion" respectively. Any patient who was discharged with more than one of the above diagnoses was classified in the highest category. Similarly, if a patient had more than one admission in the 15 year period, with differing diagnoses, then the admission with the most severe diagnosis was used. An exception to this was that admissions where the discharge diagnoses included epilepsy were discounted, as the admission might in such cases have been for observation after an epileptic convulsion, with the brain injury diagnosis recorded only as an earlier contributing cause of the epilepsy itself. Any additional nontraumatic brain injury diagnoses at discharge, in particular psychiatric diagnoses, were also registered.

Patients identified in the hospitalisation register were then screened in a national register of deaths, also for the period up to and including 1993. This register records date and cause of death. Cause of death is also categorised under a broad grouping as natural causes, accidents, suicide, or violence: in some few cases, this information is unspecified in the register.

PATIENTS

The initial search of the hospitalisations register identified 167083 persons as having had some form of traumatic brain injury as defined

Table 1 Age, sex, duration of stay in hospital, and mortality as a function of diagnostic group

\begin{tabular}{llll}
\hline & Concussion & Fracture & Lesion \\
\hline No of patients & 126114 & 7560 & 11766 \\
Median age at injury $(25 \%-75 \%)$ & $25(16-46)$ & $32(17-55)$ & $38(21-62)$ \\
Men (\%) & 60.2 & 64.6 & 68.2 \\
Median days in hospital (25\%-75\%) & $2(1-4)$ & $6(3-12)$ & $20(9-48)$ \\
No dead before 1994 (\% of total) & $13358(10.6)$ & $1056(14.0)$ & $2452(21.0)$ \\
No of suicides before 1994 (\% of total) & $750(0.59)$ & $46(0.61)$ & $99(0.84)$ \\
$\begin{array}{l}\text { Suicide (\% men) } \\
\text { Median years from injury to suicide }\end{array}$ & 68.3 & 71.7 & 77.8 \\
$\quad(25 \%-75 \%)$ & $3.6(1.4-6.7)$ & $3.0(0.9-8.0)$ & $3.3(1.1-6.3)$ \\
\hline
\end{tabular}

above. Because suicide is very rare below the age of 15 we excluded from the present analyses the 17394 cases who were born after 1978 - that is, who were less than 15 years old at the end of the study period. Thereafter, we also excluded the 4249 patients who died in hospital or who did not survive at least 1 month after discharge. These criteria left 145440 patients in the study, of whom $126114(87 \%)$ had had a concussion, $7560(5 \%)$ had had a cranial fracture and the remaining $11766(8 \%)$ had had cerebral lesions.

At the end of the study period-31 December $1993-16866$ patients $(11.6 \%$ of all who had survived until at least 1 month after hospital discharge) had died. Among these, deaths had been recorded as due to natural causes in 13261 (9.1\%) cases, accidents in 2003 (1.4\%), suicides in $895(0.62 \%)$, and violence in 68 $(0.05 \%)$; the cause was unspecified in the remaining $639(0.44 \%)$.

STATISTICAL ANALYSES

Standardised mortality ratios $(\mathrm{SMRs})^{18}$ were computed for all groups using annually published Danish tables for the period 1979 through 1993 for the total population numbers and for numbers of suicides, both of which are stratified by sex and by 5 or 10 year age bands. To examine the time interval between injury and suicide, we have employed a Cox regression analysis for proportional hazards. ${ }^{19}$

\section{Results}

Table 1 shows the age, sex, duration of stay in hospital, and mortality as a function of diagnostic group. The age at injury increased with the severity of the diagnosis, as did the proportion of males and, as would be expected, the duration of stay in hospital. Similarly, overall mortality was highest among the lesion group as was the percentage of suicide cases. It is noteworthy that, for each diagnosis, the proportion of males among the suicide cases was higher than among all cases. The median times from injury to suicide were about 3-3.5 years for all diagnostic groups and they did not differ significantly $(F(2,892)=0.67, \mathrm{p}>0.2)$.

The SMRs for suicide as a function of diagnosis and sex are shown in table 2 . The ratios were increased above population rates for all three diagnoses, being roughly tripled for the concussion and fracture groups and quadrupled for the lesion group. The ratios for females were higher than for males in all three groups. All SMR values were highly significant and the 95\% confidence intervals (95\% CIs) fell below 2.0 only for a single subgroup-males with cranial fractures.

Table 3 shows the SMR values as a function of age at injury. It is noticeable that for all three groups, the ratios were lower for patients injured before the age of 21 or after the age of 60 , than among patients injured at ages between 21 and 60 . The ratios were highest among patients with lesions injured in that age range, being about five times the population rates. With a single exception SMRs in all groups and at all ages had 95\% CIs above 
Table 2 Standardised mortality ratios for suicide as a function of diagnosis and sex

\begin{tabular}{lccllll}
\hline Sex & $\begin{array}{l}\text { Number of } \\
\text { cases }\end{array}$ & $\begin{array}{l}\text { Observed } \\
\text { No of years }\end{array}$ & $\begin{array}{l}\text { Cumulative } \\
\text { expected } \\
\text { frequency }\end{array}$ & $\begin{array}{l}\text { Observed } \\
\text { frequency }\end{array}$ & $\begin{array}{l}\text { Standardised } \\
\text { mortality ratio }\end{array}$ & 95\% CI \\
\hline Concussion & 126114 & 1026546 & 247.92 & 750 & 3.02 & $2.82-3.25$ \\
$\quad$ Men & 75972 & 627605 & 186.81 & 512 & 2.74 & $2.51-2.99$ \\
$\quad$ Women & 50142 & 398940 & 61.11 & 238 & 3.89 & $3.43-4.42$ \\
Fracture & 7560 & 62761 & 17.10 & 46 & 2.69 & $2.01-3.59$ \\
Men & 4887 & 41005 & 13.53 & 33 & 2.44 & $1.73-3.43$ \\
Women & 2673 & 21756 & 3.58 & 13 & 3.63 & $2.11-6.26$ \\
Lesion & 11766 & 79104 & 24.44 & 99 & 4.05 & $3.33-4.93$ \\
$\quad$ Men & 8030 & 54456 & 19.71 & 77 & 3.91 & $3.13-4.89$ \\
Women & 3736 & 24648 & 4.73 & 22 & 4.65 & $3.06-7.06$ \\
\hline
\end{tabular}

Table 3 Standardised mortality ratios for suicide as a function of diagnosis and age at injury

\begin{tabular}{|c|c|c|c|c|c|c|}
\hline Diagnosis age & $\begin{array}{l}\text { No of } \\
\text { cases }\end{array}$ & $\begin{array}{l}\text { Observed } \\
\text { No of years }\end{array}$ & $\begin{array}{l}\text { Cumulative } \\
\text { expected } \\
\text { frequency }\end{array}$ & $\begin{array}{l}\text { Observed } \\
\text { frequency }\end{array}$ & $\begin{array}{l}\text { Standardised } \\
\text { mortality ratio }\end{array}$ & $95 \% C I$ \\
\hline \multicolumn{7}{|l|}{ Concussion: } \\
\hline$<21$ & 49570 & 473235 & 47.53 & 102 & 2.17 & $1.77-2.61$ \\
\hline $21-40$ & 38225 & 305224 & 90.44 & 359 & 3.97 & $3.58-4.40$ \\
\hline $41-60$ & 19334 & 141070 & 62.00 & 201 & 3.24 & $2.82-3.72$ \\
\hline$>60$ & 18985 & 107016 & 47.95 & 88 & 1.84 & $1.49-2.26$ \\
\hline \multicolumn{7}{|l|}{ Fracture: } \\
\hline$<21$ & 2535 & 25824 & 2.26 & 3 & 1.33 & $0.43-4.12$ \\
\hline $21-40$ & 2036 & 16590 & 5.27 & 20 & 3.79 & $2.44-5.88$ \\
\hline $41-60$ & 1503 & 11369 & 5.20 & 14 & 2.69 & $1.59-4.55$ \\
\hline$>60$ & 1486 & 8978 & 4.38 & 9 & 2.06 & $1.07-3.95$ \\
\hline \multicolumn{7}{|l|}{ Lesion: } \\
\hline$<21$ & 2879 & 25816 & 3.17 & 11 & 3.47 & $1.92-6.27$ \\
\hline $21-40$ & 3308 & 24244 & 7.50 & 35 & 4.67 & $3.35-6.50$ \\
\hline $41-60$ & 2444 & 15130 & 6.96 & 36 & 5.17 & $3.73-7.17$ \\
\hline$>60$ & 3135 & 13914 & 6.82 & 17 & 2.49 & $1.55-4.01$ \\
\hline
\end{tabular}

unity, the exception being patients with lesions injured before the age of 21 , among whom there were only three suicide cases.

Among all 145440 patients, 8684 (6\%) also had a psychiatric diagnosis. In most patients $(\mathrm{n}=7421 ; 5 \%)$ this concerned substance misuse (ICD 291 alcoholic psychosis, ICD 303 alcoholism, or ICD 304 drug dependence), the most common single diagnosis being inebriation at the time of admission (ICD 303.90; $\mathrm{n}=5165 ; 3.6 \%)$. Substance misuse was more common among the lesion group $(n=681$; $5.8 \%)$ than among the fracture group $(n=312$; $4.1 \%)$ or the concussion group ( $\mathrm{n}=6428$; $5.1 \%)\left(\chi^{2}(2)=26.3 ; \mathrm{p}<0.001\right)$. However, table 4 shows that the presence of a codiagnosis of substance misuse markedly increased the

Table 4 Standardised mortality ratios for suicide as a function of diagnosis and substance misuse

\begin{tabular}{|c|c|c|c|c|c|c|}
\hline $\begin{array}{l}\text { Diagnosis of } \\
\text { Substance misuse }\end{array}$ & $\begin{array}{l}\text { Number } \\
\text { of cases }\end{array}$ & $\begin{array}{l}\text { Observed } \\
\text { No of years }\end{array}$ & $\begin{array}{l}\text { Cumulative } \\
\text { expected } \\
\text { frequency }\end{array}$ & $\begin{array}{l}\text { Observed } \\
\text { frequency }\end{array}$ & $\begin{array}{l}\text { Standardised } \\
\text { mortality ratio }\end{array}$ & $95 \% C I$ \\
\hline \multicolumn{7}{|l|}{ Concussion: } \\
\hline No & 119686 & 975890 & 228.90 & 654 & 2.86 & $2.67-3.09$ \\
\hline Yes & 6428 & 50656 & 19.03 & 96 & 5.05 & $4.13-6.16$ \\
\hline \multicolumn{7}{|l|}{ Fracture: } \\
\hline No & 7248 & 60395 & 16.12 & 42 & 2.61 & $1.93-3.53$ \\
\hline Yes & 312 & 2366 & 0.99 & 4 & 4.05 & $1.52-10.80$ \\
\hline \multicolumn{7}{|l|}{ Lesion: } \\
\hline No & 11085 & 74948 & 22.69 & 86 & 3.79 & $3.07-4.68$ \\
\hline Yes & 681 & 4156 & 1.75 & 13 & 7.44 & $4.32-12.82$ \\
\hline
\end{tabular}

Table 5 Standardised mortality ratios for suicide for lesion cases as a function of duration of stay in hospital

\begin{tabular}{lllllll}
\hline Stay in hospital & $\begin{array}{l}\text { No of } \\
\text { cases }\end{array}$ & $\begin{array}{l}\text { Observed } \\
\text { No of years }\end{array}$ & $\begin{array}{l}\text { Cumulative } \\
\text { expected } \\
\text { frequency }\end{array}$ & $\begin{array}{l}\text { Observed } \\
\text { frequency }\end{array}$ & $\begin{array}{l}\text { Standardised } \\
\text { mortality ratio }\end{array}$ & $95 \%$ CI \\
\hline$<1$ week & 2163 & 15342 & 3.99 & 14 & 3.51 & $2.08-5.92$ \\
$1-4$ weeks & 4952 & 33411 & 10.41 & 38 & 3.65 & $2.66-5.02$ \\
$1-3$ months & 3138 & 20145 & 6.74 & 31 & 4.60 & $3.23-6.54$ \\
$>3$ months & 1513 & 10204 & 3.30 & 16 & 4.85 & $2.97-7.92$ \\
\hline
\end{tabular}

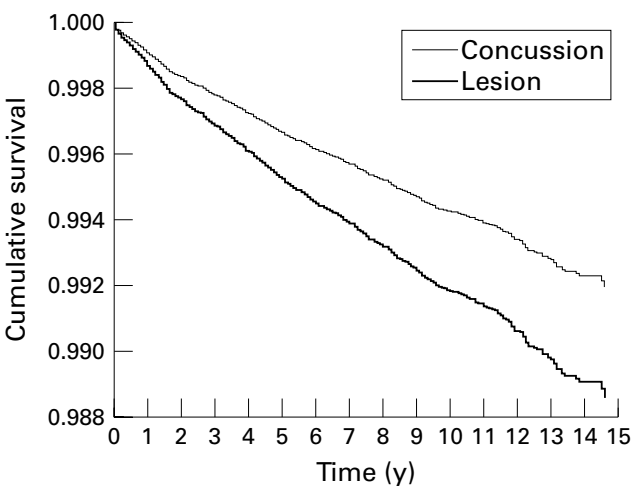

Figure 1 Cumulative proportional hazards for suicide in the concussion and lesion groups.

SMRs for suicide in all three groups. The highest SMR, greater than 7, was that for the lesion group, although the small numbers in the fracture and lesion groups were necessarily associated with large $95 \%$ CIs.

As shown in table 5 there seemed, among the lesion group, to be a monotonically increasing risk of suicide in proportion to duration of stay in hospital. However, the wide $95 \%$ CIs associated with the SMRs makes this interpretation tenuous.

To investigate the time course of suicide after injury we performed a Cox regression analysis in which sex, age at injury, and the presence of a substance misuse codiagnosis were entered in a first block before the inclusion of diagnostic group. In view of its apparently non-linear function, age at injury was entered as a category variable using the groupings shown in table 3. The analysis showed that diagnostic group made a significant improvement $(p=0.004)$ to the overall model after the inclusion of sex, age at injury, and substance misuse. The lesion group had a significantly higher rate of suicides than both the concussion group (hazard ratio $=1.42,95 \%$ CI $1.15-1.75$ ) and the fracture group (hazard ratio $=1.50,95 \% \mathrm{CI}$ 1.06-2.13). The influence of sex, age at injury, and the presence of substance misuse on these ratios was not very substantial; before their inclusion in the analysis the hazard ratio for the lesion group relative to the concussion group was 1.67 ( $95 \% \mathrm{CI} 1.36-2.06)$ and for the lesion group relative to the fracture group 1.66 (95\% CI 1.17-2.35).

The survival functions (specific for suicide) for the concussion and fracture groups were found to be virtually identical. Figure 1 illustrates the contrasting functions for the concussion and lesion groups across the maximum of 15 years of follow up; both functions, although differing in slope, were essentially linear. Thus, there was no strong evidence for a specific risk period for suicide after injury in any of the groups.

The possibility exists, in cases of suicide after a traumatic brain injury, that the injury itself might have been the result of an unsuccessful suicide attempt. We have been able to examine this possibility, as the hospitalisation register has included, from 1987 onwards, a coding of whether the injury was self inflicted. Among all three diagnosis groups combined 48298 cases 
occurred in 1987 or later, and of these only 369 $(0.8 \%)$ were recorded as having been self inflicted injuries. Seven of these 369 (1.9\%) were subsequent suicides whereas there were 134 suicides among the remaining 47929 non-self inflicted cases $(0.3 \%)$. Although this association is highly significant (odds ratio $=6.9,95 \%$ CI 3.2-14.8) it is clear that for only a numerically negligible proportion of cases within our sample could the brain injury have been the result of a failed suicide attempt.

\section{Discussion}

The present study, although large scale and nationally representative, has some limitations. Firstly, the hospitalisation register is not completely accurate, particularly effecting the diagnosis grouping we have used here. Thus, from a subsample within the present study, involving review of the original hospital records, we have estimated that about $10 \%$ of coded diagnoses of intracranial lesions may be incorrect, especially involving overrecording of the ICD-8 854 diagnosis for "non-specific intra-cranial lesions" where a concussion diagnosis (ICD-8 850) would have been appropriate. Conversely, there may also be some underrecording of cerebral lesions. In a smaller earlier study ${ }^{14}$ up to one third of patients who had a post-traumatic amnesia exceeding 1 week were found to be recorded with only concussion or cranial fracture diagnoses. The register itself contains no data concerning depth or duration of coma, nor duration of posttraumatic amnesia (we are currently conducting an intensive study of a representative sample of the patients with brain injury in which we are gathering such data directly from the hospital records). The lack of post-traumatic amnesia data is especially unfortunate considering the high predictive value of that measure for outcome after traumatic brain injury. ${ }^{14}$

Another issue which needs to be considered is the possible underreporting of suicides. Social and religious disapprobation of suicide is common in many cultures. ${ }^{720}$ Although this is perhaps less true of Denmark than elsewhere, it remains the case that within our population some suicides-for example, from drug overdoses, drowning, and falls from high places - could have been erroneously recorded as accidental deaths. It should also be emphasised that it has not been possible for us within the present study to investigate other potentially related factors such as unemployment and marital status.

Within the constraints of these considerations, however, our results do seem to permit some clear conclusions about suicide after a traumatic brain injury, given survival through the acute phase.

Perhaps the most striking finding has been the increased rate of suicides among patients who have had no more than a concussion, leading typically to only a single day in hospital for observation, or a cranial fracture with no identified cerebral lesion. Our findings for the concussion and fracture groups have more similarities than differences and we consider them together, before discussing the findings for the lesion group.

The increased suicide rates for the concussions and fracture groups, by a factor of two or more relative to the general population, were found to a greater or lesser extent for both sexes and for all age groups. Particularly in the case of concussions there can hardly be any direct link between having sustained the injury and the subsequent suicide, and the association must have arisen from concomitant and perhaps premorbid characteristics.

Achté $e t a l^{\beta}$ noted that some characteristics, such as "broken homes" during childhood and alcohol misuse, occurred with greater frequency among their suicide patients with brain injury. They commented that "there is reason to suppose that a considerable proportion of those who later committed suicide had even prior to the injury manifested deviant psychic features". This is certainly supported by our finding of the substantial contribution towards suicide risk of a codiagnosis of substance misuse, in most cases no more than a registration that the patient was inebriated at admission. The associations of substance misuse with both traumatic brain injury and with suicide are well documented..$^{71}$

Mortality rates were greater for females than for males, this despite the fact that there were relatively fewer suicides among females than among males in our population. Similarly Hartkopp et $a l^{22}$ found increased mortality rates for females in a Danish cohort of patients with spinal injury. They speculated that this may be because "women build their self image much more on their physical attractiveness than men" and therefore find it more difficult to cope with the consequences of a spinal cord injury. This explanation will certainly, however, not account for the relatively greater mortality rate among females with a concussion. We suspect that concussion may be more strongly related to psychosocial disadvantage among women than among men, and thereby be more strongly predictive of suicide.

The effect of age may also be related to psychosocial disadvantage. Mortality rates for suicide are greater among patients who have traumatic brain injuries sustained at ages between 20 and 60 than those having such injuries at younger or older ages. We have elsewhere shown that concussions sustained in adolescents are less associated with premorbid cognitive deficit than concussions sustained by young adults, ${ }^{23}$ a result which we interpreted to suggest that the injuries in the first group were more often associated with play and sports and less associated with alcohol, violence, and other psychosocial factors. The present results are consistent with this view. Similarly milder traumatic brain injuries among older people may also be relatively more often the result of physical frailties, accident proneness, and sheer ill luck-comparatively unrelated to psychosocial disadvantage.

For the lesion group, it is noticeable that mortality rates for suicide were consistently higher than for the concussion and fracture groups, for both sexes and at all ages. To the 
extent that premorbid psychosocial factors are equated across the three groups, then the higher rate of suicide for the lesion group implicates the direct consequences of the injury itself on the suicide. This interpretation is supported by the clinical evidence stemming from smaller studies of similarly severe traumatic brain injuries. ${ }^{11} 12$

That the suicide rates within the lesion group tended to increase with the severity of the injury, as gauged by the duration of stay in hospital, is also consistent with this interpretation. We have elsewhere reported duration of hospital stay after traumatic brain injury to correlate consistently with poorer long outcome in terms of education, employment, and disability. ${ }^{24}{ }^{25} \mathrm{It}$ might have been expected that suicide rate would decline at some level of severity where the person with brain injury would be lacking the cognitive and physical apparatus for the act. That we could not identify such a level within our data is probably due to the limitations of duration of stay in hospital as a measure of severity of injury relative to the generally much more sensitive post-traumatic amnesia. ${ }^{14}$

From their clinical evidence both Tate $e t ~ a l^{12}$ and Klonoff and Lage ${ }^{11}$ have suggested that, where relatively severe traumatic brain injury results in subsequent suicide, it is psychologically reactive to the identity crises and generalised social disruption experienced in such cases, rather than any more specific neuropsychological mechanism such as greater impulsivity consequent on frontal lobe injury. Similarly, in their larger study, Achté et $a l^{8}$ found suicide to be related to the severity of the injury but not its localisation.

Although our evidence supports the view that suicide is indeed more common after a relatively severe traumatic brain injury we could find no evidence of a risk period. It is often suggested that the full impact of the consequences of such an injury is not felt immediately but only after some years of experiencing disappointments and fiascos, of ultimately confronting the fact that improvement, characteristic of early postinjury phases, will not continue to the point where full premorbid functioning returns. However, our present evidence suggests that the risk of suicide is a constant, continuing for at least the maximum of 15 years follow up we are reporting here. It is similarly noteworthy that Achte $e t a l^{\beta}$ found the suicide risk actually to increase to a maximum of 15 years after injury, an interval which, as Tate $e t a l^{12}$ note, was probably more related to the chronological age of his sample 15 years after injury ( people then in their 40s and 50s) rather than the time interval itself.

In summary, we have found increased rates of suicide among patients with relatively severe traumatic brain injury. Present evidence suggests that no small degree of this increase may be due to premorbid psychosocial factors, as the increase is also present in patients with concussion and cranial fractures. The absolute magnitude of the rates is not of alarming proportions, being about $1 \%$ over a 15 year period. Nonetheless, as Tate $e t a l^{12}$ remark, "the small magnitude in no way corresponds to the seriousness of the problem" and awareness of a suicide risk should be present in the assessment of any traumatic brain injury.

This work was approved by the ethics committee for Copenhagen and Frederiksberg and was supported by a grant from the Danish Ministry of Social Services and an award from the Inge Lehmann Legacy. It was completed while the first author was at the Medical Research Council's Cognition and Brain Sciences Unit at Cambridge, UK.

1 van Reekum R, Bolago I, Finlayson MA, et al. Psychiatric disorders after traumatic brain injury. Brain Inj 1996;10:319-27.

2 Ownsworth TL, Oei TP. Depression after traumatic brain injury: conceptualization and treatment considerations. Brain Inj 1998;12:735-51.

3 Fedoroff JP, Starkstein SE, Forrester AW, et al. Depression in patients with acute traumatic brain injury. Am f Psychiatry 1992;149:918-23.

4 Persinger MA. Sense of a presence and suicidal ideation following traumatic brain injury: indications of righthemispheric intrusions from neuropsychological profiles. Psychol Rep 1994;75:1059-70.

5 Mann JJ, Waternaux C, Haas GL, et al. Toward a clinical model of suicidal behavior in psychiatric patients. Am $\mathcal{f}$ Psychiatry 1999;156:181-9.

6 Burns S, Kappenberg R, McKenna A, et al. Brain injury: personality, psychopathology and neuropsychology. Brain Inj 1994;8:413-27.

7 Harris EC, Barraclough B. Suicide as an outcome for mental disorders. A meta-analysis. Br F Psychiatry 1997;170. $205-28$

8 Achté KA, Lönnqvist J, Hillbom E. Suicides following war brain-injuries. Acta Psychiatr Scand Suppl 1971;225:1-94.

9 Roberts AH. Severe accidental head injury. An assessment of long-term prognosis. London: MacMillan, 1979.

10 Wilson BA. Life after brain injury: long term outcome of 101 people seen for rehabilitation 5-12 years earlier. In: Fourez J, Page $\mathbf{N}$, eds. Treatment issues and long term Press, 1994:1-6.

11 Klonoff PS, Lage GA. Suicide in patients with traumatic brain injury: risk and prevention. $\mathcal{F}$ Head Trauma Rehabil 1995;10:16-24.

12 Tate R, Simpson G, Flanagan S, et al. Completed suicide after traumatic brain injury. 7 Head Trauma Rehabil 2000;12:16-28.

13 Moscicki EK. Identification of suicide risk factors using epidemiologic studies. Psychiatr Clin North Am 1997;20:499 517.

14 Engberg A. Severe traumatic brain injury: epidemiology, external causes, prevention, and rehabilitation of mental and physical sequelae. Acta Neurol Scand Suppl 1995;164 $1-151$.

15 Diekstra RF. The epidemiology of suicide and parasuicide. Acta Psychiatr Scand Suppl 1993;371:9-20.

16 Sorensen SB, Kraus JF. Occurrence, severity, and outcomes of brain injury. F Head Trauma Rehabil 1991;6:1-10.

17 Kraus JF, McArthur DL. Epidemiologic aspects of brain injury. Neurol Clin 1996;14:435-50.

18 MacMahon B, Trichopoulos D. Epidemiology: principles and methods. Boston: Little, Brown, 1996.

19 Parmar MKB, Machin D. Survival analysis: a practical approach. Chichester UK: Wiley, 1995.

20 Neeleman J, Lewis G. Suicide, religion, and socioeconomic conditions. An ecological study in 26 countries, 1990. $f$ Epidemiol Community Health 1999;53:204-10.

21 Leon-Carrion J. An approach to the treatment of affective disorders and suicide tendencies after TBI. In: LeónCarrión J, ed. Neuropsychological rehabilitation: fundamentals, innovations and directions. Delray Beach, FL: GR/St Lucie Press 1997:415-29.

22 Hartkopp A, Bronnum-Hansen H, Seidenschnur AM, et al. Suicide in a spinal cord injured population: its relation to functional status. Arch Phys Med Rehabil 1998;79:1356-61.

23 Teasdale TW, Engberg A. Duration of cognitive dysfunction after concussion, and cognitive dysfunction as a risk factor: a population study of young men [see comments]. BMF 1997;315:569-72.

24 Teasdale TW, Engberg AW. Disability pensions in relation to traumatic brain injury: a population study. Brain Inj 2000; 14:363-72.

25 Teasdale TW, Hansen HS, Gade A, et al. Neuropsychological test scores before and after brain-injury rehabilitation in relation to return to employment. Neuropsychological Rehabilitation 1997;7:23-42. 